\title{
THE FIRST APPLICATION OF THE ELECTRODYNAMIC WAGON RETARDER IN POLAND
}

The article discusses design and installation method of the EDG Electrodynamic Wagon Retarder at the railway siding of the Power Plant Rybnik. It is the first structure of its kind in Poland. Up to now mostly hydraulic brakes have been used in Poland. They were difficult to operate and hardly environmentally friendly due to contamination and noise. Electrodynamic wagon retarders are free from such defects. The issue of introducing new railroad brake construction in Poland is very important because the Polish Railway Lines (PLK) are confronted with the need of devices modernization on a humps. The German railways' experience confirms the effectiveness of this type of brake. Especially the field tests in Germany and Poland show that the electrodynamic retarders do not have a negative impact on the occupancy control system.

\section{Introduction}

At present, mostly hydraulic brakes are used in marshalling of wagons. They are generally in the form of platforms, sometimes poppet brakes. Maintenance of the hydraulic brakes is difficult due to their outdated design. They also constitute a threat to the environment. The threat consists in brakes utilising oil, which leaks out to the environment, and both oil-feeding system and retarder shoes generate noise, which is a nuisance to people living nearby. To eliminate the said disadvantages, the Power Plant Rybnik has erected a test installation of the electrodynamic wagon retarder system type EDG. It is the first structure of its kind in Poland.

The article discusses applications and test results of electromagnetic radiation generated by the retarder, with emphasis on the requirements regarding the protection of persons working near the retarder.

\section{Characteristic of EDG Retarder}

The purpose of the electrodynamic wagon retarder (EDG) (Fig. 1), considering the safety requirements and quality of marshalling, is to reduce the speed of individual wagons and groups of wagons in gravitational marshalling system. The system is already proven, and it does not require frequent repairs and maintenance. The major advantages of electrodynamic wagon retarders are lownoise missions during operation, both during tests of retarding jaws and during actual retarding of wagons. The symmetrical braking force of the jaws (two-sided retarders) continuously affects wagon wheels, eliminating the effect of wheel-set lifting while braking. The smoothly applied braking force and additional magnetic effect on the wagon wheel prevent the transfer of forces from a rolling wagon onto the retarder and its foundation in pulses.

Basic features of the Electrodynamic Retarder EDG - 93 are summarized below:

- It can be used as a service, group or an additional brake;

- It can be operated as a destination and distance brake;

- It enables manual, semi-automatic, or fully automatic control;

- Its installation length is of $5 \mathrm{~m}$ to $20 \mathrm{~m}$ (by $2.5 \mathrm{~m}$ );

- The maximum height of the situate retarder beams to the lateral side of a railway wagon wheel ring is equal to $63 \mathrm{~mm}$;

- It can function as a retarder when installed on both rails. Braking forces are generated by 3 simultaneous factors: friction between the wheels and the retarder beams, friction between the retarder beams and the retarder body, caused by the cutting of the wheel through braking beams and the eddy current;

- It is fitted with electric actuators of braking beams;

- It is fitted with electronic retarder control, including the Profibus connection system;

- It is fitted with electronic controls.

The main elements of the construction (Fig. 2):

- Retarder (consists of a body of the retarder, the bearing beams of retarder and excitation winding) (1);

- Container with the control devices and power (rectifier) (2);

- Operation place with a control panel (touch screen) (3).

\section{Operating position:}

- Locomotive passage position - in that position, braking beams move freely in the bodies, and the retarder can be driven through with no resistance whatsoever;

\footnotetext{
* Jerzy Mikulski, Jakub Mlynczak

Faculty of Transport, Silesian University of Technology, Katowice, Poland, Email: jerzy.mikulski@polsl.pl
} 


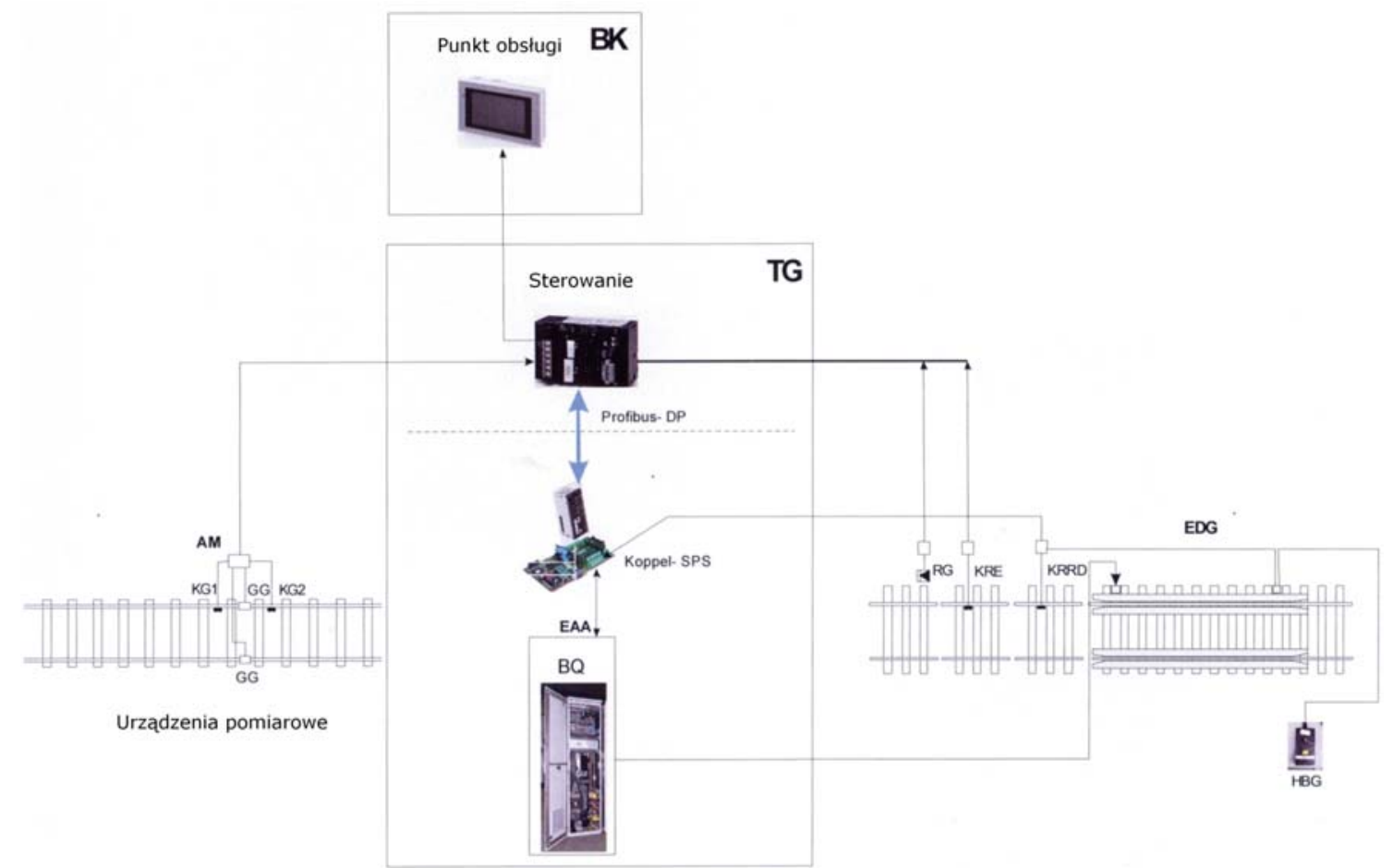

Fig. 1 Diagram of electrodynamic retarder installation at the Power Plant Rybnik;

$E D G$ - Electrodynamic Wagon Retarder, AM - system providing detection of wheel load, KGI - wheel detection sensor (on-switch), $K G 2$ - wheel detection sensor (off-switch), GG - weight sensor, $R G$ - radar, KRE - wheel detection sensor (entrance),

$K R R D$ - wheel detection sensor (entrance, reserve), $T G$ - technical building, BQ - rectifier.

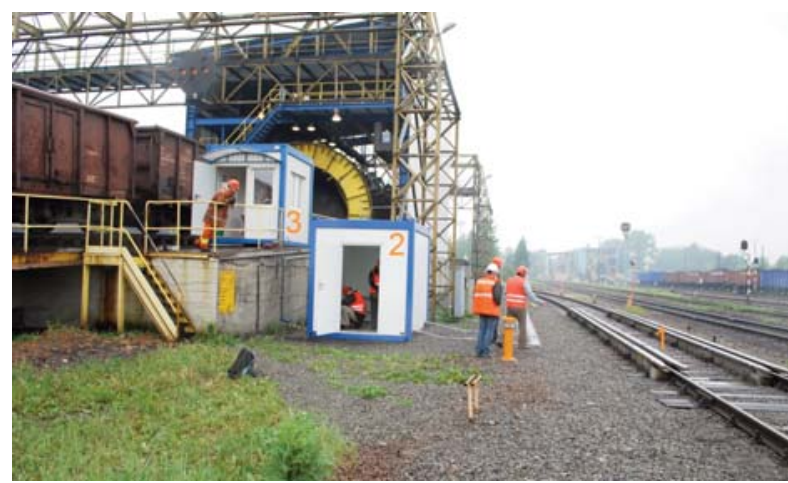

Fig. 2 Electrodynamic Wagon Retarder system at the railway siding of the Power Plant Rybnik.

- Braking position - DC voltage is supplied to the retarder, braking beams are moved to the braking position.

Controls:

- Commands are sent from the control panel and via respective controls;

- There is manual enforcement of indicated or calculated optimum (target) speed of leaving the retarder;
- The required braking force is reached by the electromagnetic force field.

\section{Brief characteristics of the installation}

The purpose of the EDG retarder (Fig.3) at the railway siding of the Power Plant Rybnik is to brake the wagons going down the cradle of tippler 3 to one of the destination tracks. Tracks of the remaining tipplers are fitted with ETH retarders.

The EDG retarder is erected on the track. Between the retarder and switch, there is a manual brake skids launcher acting as the braking component in the event of EDG retarder failure.

The track where the EDG retarder is erected is an access track to destination tracks for empty wagons. Leaving the tippler (Fig.3 b, 4a), empty wagons pass through the cradle (Fig. 4b), where the direction of wagon movement is changed. Wagons moving from the cradle to the destination tracks (Fig. 5) need to have the speed suitable for the active length of tracks, i.e. for wagons that are supposed to park at the end of the destination track, such speed is to be high enough to allow the wagon to travel the required distance; in the event when the track is already full, such speeds can be lower. Until now, the brake skids launcher was used for that purpose. The said solution features low accuracy in the selection 

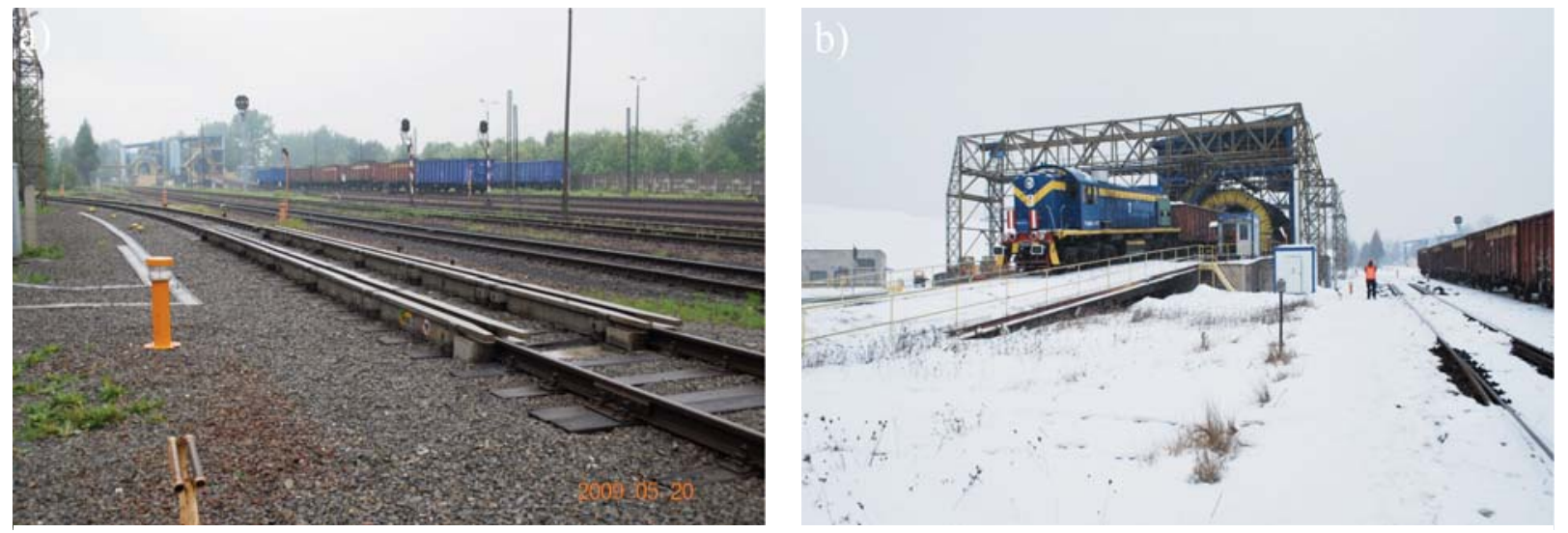

Fig. 3 a) EDG retarder, b) Tippler
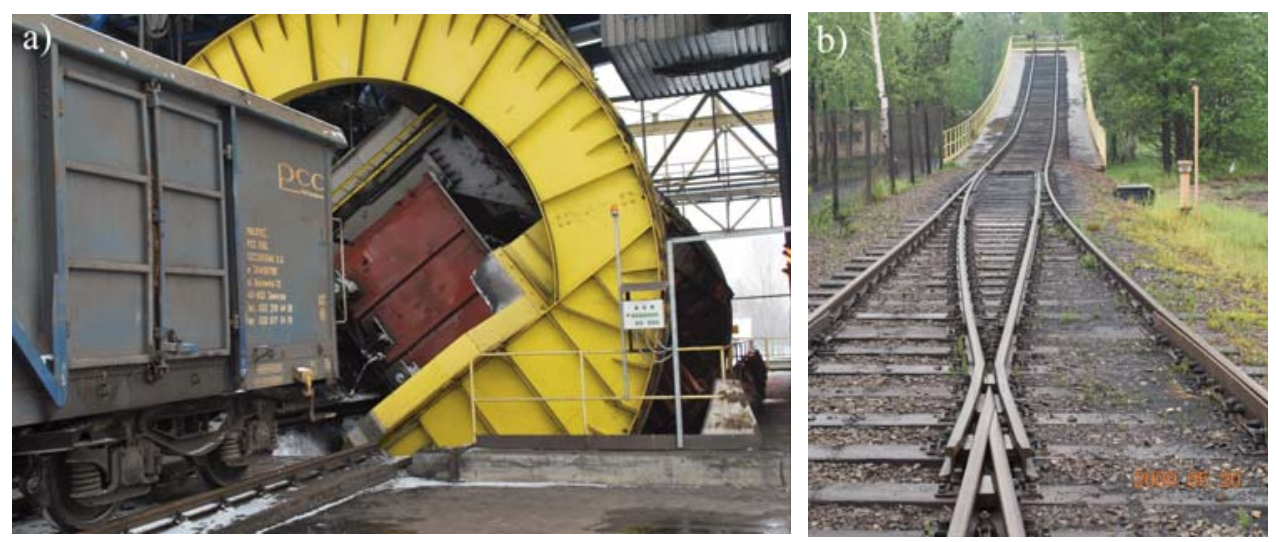

Fig. 4 a) Wagon on tippler, b) Cradle

of speed of marshalled wagons, resulting in the need to push the wagons further (in case of insufficient speed), or in wagons hitting the buffers with excessive force, resulting in excessive buffer wear and noise.

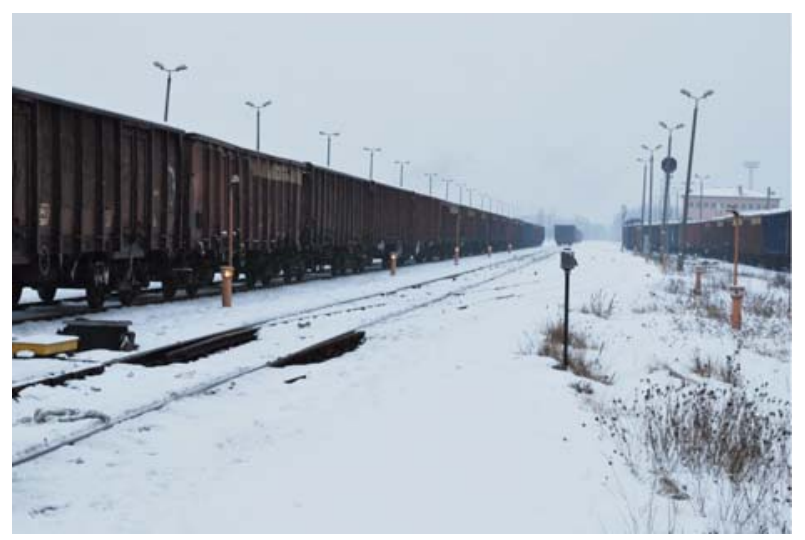

Fig. 5 Unloading rail tracks

\section{Assessment of Parameters of the Electrodynamic Retarder EDG}

The retarder manufacturer has a package of documents evidencing that the EDG retarder meets the parameters referring to electromagnetic compatibility, the requirements regarding electronic traffic control systems, software for traffic control systems, as well as safety and reliability.

\section{Electromagnetic Compatibility}

Pursuant to those documents, the EDG Wagon Retarder, including the accessories, meets the requirements regarding electromagnetic compatibility as per the scope of standards [4].

\section{Software and hardware}

The EDG Wagon Retarder meets the requirements of railway standards [5], [6] and [7] with regard to reliability, availability, maintenance susceptibility and safety, and the software for railway traffic control systems, including electronic traffic control systems.

\section{Permanent way and structure clearance}

It is to be noted that the EDG Wagon Retarder was fitted with a diagnostic system of permanent way diagnostic system notifying 
the operator on inter alia defective track sub-base, or material differences in the condition of rail courses of both retarder rails. In addition, the manufacturer is executing the retarder in all kinds of rails, depending on local conditions, in order to avoid implementation of the intermediate rail.

A radar is used in the EDG Wagon Retarder to measure the speed of marshalled wagons. The radar is erected so as to ensure the keeping of structure clearance.

It is to be stated that the device meets the requirements of Polish regulations regarding the permanent way and clearance as per the scope of assessed requirements.

\section{Measurements of the Electromagnetic Field Intensity at the Retarder and Supply Point}

Measurements of the electromagnetic field were carried out to the requirements of standards [9] and [10]. The measurements were carried out for the wagon retarder and the adjacent area, as well as for the control room and control point. The layout of measuring points at the retarder is shown in Fig. 6. The measurement of the static magnetic field is shown in Fig. 7a and the rotating magnetic field in Fig. 7b. Results of measurements for the wagon retarder are shown in Table 1. During the measurements in the control room and at the control point, no magnetic field exceeding the background value was observed.

Measuring points 1 to 6 are located, respectively, 0.1, 0.3, 0.5, $1,2,3 \mathrm{~m}$ from the rail, at the height of $0.3 \mathrm{~m}$.

No variable electromagnetic radiation exceeding the background level was observed at the retarder.

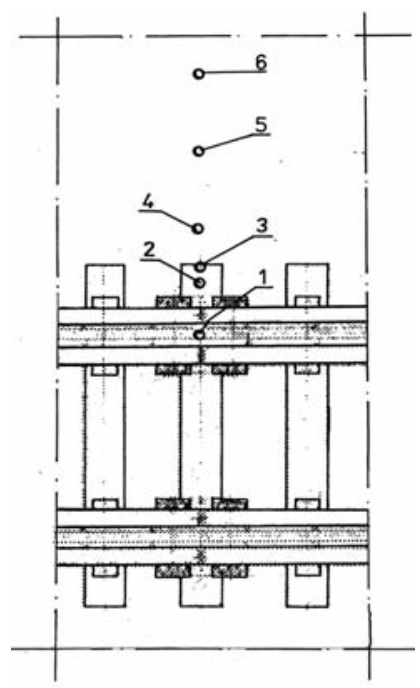

Fig. 6 Measurement zones

The zone limits for the work stations are:

- The limit between the safe zone and intermediate zone is $3.3 \mathrm{mT}$;

- The limit between the intermediate zone and the risk zone is 10 $\mathrm{mT}$;

- The limit between the risk zone and the hazard zone is $100 \mathrm{mT}$.

In the safe zone, workers can stay without any restrictions. In the intermediate zone, workers can stay for 8 hours during work shift. Measurements suggest that the range of the intermediate zone is up to $1 \mathrm{~m}$ from the retarder, which means that during the occurrence of the magnetic field (passage of wagon), workers cannot

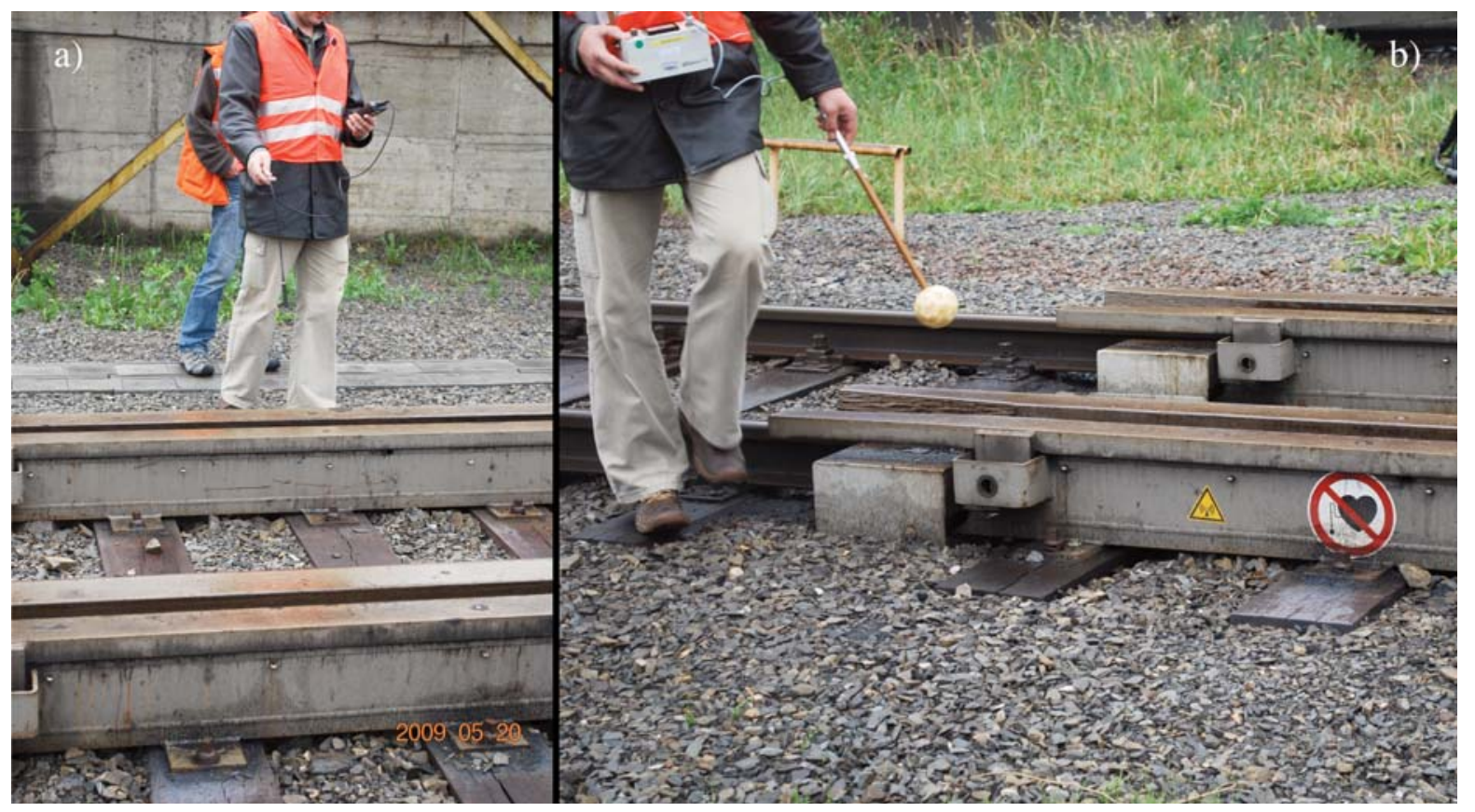

Fig. 7 Measurement of the a) static magnetic field b) rotating magnetic field 
stay in this zone. Regarding other measuring points, the respective zones are considered safe.

Table 1

\begin{tabular}{|c|c|c|}
\hline \multicolumn{3}{|c|}{ Results of measurements of magnetic fields around the wagon retarder } \\
\hline \multirow[t]{2}{*}{ Item } & $\begin{array}{l}\text { Maximum } \\
\text { intensity }\end{array}$ & Characteristics of the location of measuring stack \\
\hline & {$[\mathrm{mT}]$} & \\
\hline \multirow{2}{*}{1} & 4.1 & Idle run \\
\hline & 200 & Simulation of max. load \\
\hline \multirow{3}{*}{2} & 0.57 & Idle run \\
\hline & 11.2 & Braking of wagon \\
\hline & 12.1 & Simulation of max. load \\
\hline \multirow{3}{*}{3} & 0.29 & Idle run \\
\hline & 2.8 & Braking of wagon \\
\hline & 3.3 & Simulation of max. load \\
\hline \multirow{3}{*}{4} & 0.28 & Idle run \\
\hline & 2.2 & Braking of wagon \\
\hline & 3.2 & Simulation of max. load \\
\hline \multirow{3}{*}{5} & 0.23 & Idle run \\
\hline & 1.2 & Braking of wagon \\
\hline & 1.4 & Simulation of max. load \\
\hline \multirow{3}{*}{6} & 0.12 & $3 \mathrm{~m}$ from the rail (idle run) \\
\hline & 0.21 & $3 \mathrm{~m}$ from the rail (braking of wagon) \\
\hline & 0.4 & $3 \mathrm{~m}$ from the rail (simulation of maximum load) \\
\hline
\end{tabular}

\section{Conclusion}

The first wagon retarder installation in Poland was executed at the railway siding of the Power Plant Rybnik. The retarder is used to reduce the speed of empty wagons leaving the tippler cradle. Such a location of the test field enables testing of the solution in Polish conditions.

In case of this application, the risk connected with possible brake failure is minimised since only empty coal wagons, the speed and weight of which are low, are being retarded. As the investor is aware of the fact that such a solution is new in Poland, the brake skids launcher installation is maintained to increase the reliability of operation. That shall increase the safety of the railway siding at the Power Plant Rybnik.

The dimensions of the retarder (including weight) and requirements regarding supply parameters render the laboratory tests of the device impossible. It was only the erection of the test installation at the facility that enabled the performance of the functional tests of the device.

The test installation enabled also the measurements of the intensity of the magnetic field around the EDG wagon retarder and in the control room. The said measurements carried out according to relevant standards enabled to ensure that the solution examined is safe to the operating personnel. In the control room and at the control point, no electromagnetic radiation exceeding the background was observed, too.

\section{References}

[1] Regulation by Minister of Infrastructure on the scope of examinations required to obtain Commissioning Certificates of types of buildings and facilities designated for management of railway traffic and types of railway vehicles, dated 12 October 2005 (JoL No. 212, item 1772 , dated $12 / 10 / 2005$ )

[2] Regulation by Minister of Infrastructure on general engineering conditions for operation of rolling stock, dated 12 October 2005 (JoL No. 212, item 1771, dated 12/10/2005).

[3] Rail Transport Act dated 28 March 2003.

[4] EN 50121 - Railway Applications - Electromagnetic Compatibility

[5] EN 50126 - Railway Applications - Specification of reliability, availability, maintenance susceptibility and safety

[6] EN 50128 - Railway Applications. Communications, signalisation and control systems - Programmes for railway control and protection systems.

[7] EN 50129 - Railway Applications - Communication, data processing and traffic control systems. Safety-related electronic traffic control systems.

[8] PN-T-06580-1:2002 - Protection of work in fields and electromagnetic radiation with frequency $0 \mathrm{~Hz}$ to $300 \mathrm{GHz}$. Part 1: Terminology

[9] PN-T-06580-3:2002 - Protection of work in fields and electromagnetic radiation with frequency $0 \mathrm{~Hz}$ to $300 \mathrm{GHz}$. Part 3: Terminology

[10] OPERATIONAL AND ENGINEERING DOCUMENTATION Electrodynamic Wagon Retarder EDG - 93 by FEW for application in humps, Rev. 01/2008, Wichary Technologies. Siemianowice, 2008.

[11] Engineering Conditions for Execution and Acceptance of Electrodynamic Wagon Retarder Type EDG - 93, Rev. 01/2008, Wichary Technologies. Siemianowice, 2008. 